\title{
DEBATES
}

\section{Grupo focal: algumas notas sobre questões práticas}

\author{
Focus group: some notes on practical issues
}

\section{Ivete Manetzeder Keil}

\section{Resumo}

Este texto pretende contribuir com algumas notas sobre questóes práticas para facilitar o entendimento da técnica de grupo focal. Sendo ele introdutório, o seu plano é simples, abordando uma breve definição e caracterização da técnica, alguns procedimentos básicos para a sua utilização, as vantagens e desvantagens consideradas mais frequentemente e, finalmente, algumas pistas para a análise dos dados.

\section{Palavras-chave}

Grupos Focais; Pesquisa Qualitativa; Técnica de Pesquisa.

\section{Abstract}

This article aims to contribute, with some notes on practical issues, to more easily understand the focus group technique. As it is introductory, its plan is very simple, briefly addressing the definition and technique characteristics and some basic procedures for its use, the most frequently considered advantages and disadvantages, and finally some clues to the data analysis.

\section{Keywords}

Focus Group; Qualitative Research; Research Technique. 


\section{Introdução}

Parece-me extremamente pertinente que se tenha incluído na presente obra a técnica do Grupo Focal (Focus Group), posto que se trata de uma técnica cada vez mais utilizada por pesquisadores de diferentes campos do conhecimento. O grupo focal tanto pode ser aplicado na perspectiva exploratória como na de clínica (semelhante ao grupo operativo de PICHON-RIVIËRE, 1998), de marketing, entre outras; tanto pode ser fonte única de coleta de dados como fonte principal ou, ainda, fonte complementar. Tal técnica responde às exigências críticas que visam enfatizar e tornar públicas as múltiplas vozes produzidas na proximidade com o outro, na empatia e na dinâmica de um encontro que visa à discussão de temas préestabelecidos pela própria pesquisa e seus objetivos. O grupo focal é uma técnica de pesquisa que permite, ao mesmo tempo, a expressão da alteridade e a compreensão da subjetividade. ${ }^{1}$

No meu ofício de pesquisadora, utilizei e tenho utilizado com muita constância a técnica de grupo focal porque os pontos de vista que ele possibilita mostram de fato uma reflexividade cognitiva bastante importante para a pesquisa, difícil de ser alcançada por outras técnicas. Ou seja, o deixar viver o experimento na dinâmica do encontro favorece a emergência das opinióes dos participantes em interação, apontando para um grau significativo de confiabilidade em relação aos dados. $\mathrm{Na}$ verdade, trata-se de um encontro com um outro (o grupo), que figura como interlocutor privilegiado, tendo como ponto central a revelação de variadas visões e pontos de vistas em relação a uma experiência, um acontecimento, um evento, uma prática, um produto. Claro está que o grupo focal, por ser uma técnica qualitativa, não se mostra adequado para estudar a frequência em que determinadas percepçóes, opiniốes e comportamentos ocorrem.

A palavra do grupo constituído por um número ideal de interlocutores, o que ele expressa em relação a comportamentos, crenças, percepções, atitudes, enfim, sua potência de dizer algo sobre um tema específico, tendo em vista sua compreensão, interpretação, explicação, argumentação, é decisiva para o trabalho do pesquisador em determinados tipos de pesquisa. Mesmo o silêncio de algum participante em relação a um tópico fala sobre algo. Aliás, gestos, expressóes faciais, posturas corporais, inflexóes na voz etc. devem ser considerados, uma vez que constituem uma linguagem bastante significativa por ser simbólica.

\footnotetext{
${ }^{1}$ Esta questão será aprofundada no livro que estou escrevendo - sobre a técnica dos grupos focais - para a Série Pesquisa Atual / Escritos Editora.
} 
De fato, a dinâmica que a técnica propõe, isto é, a palavra em debate e sua circulação entre os participantes, eles próprios geradores de novas questôes e produtores de novas concepçóes sobre o tema, na busca de respostas aos eixos temáticos propostos, e as demais linguagens concorrentes, revela sua incontestável profundidade. É justamente isso que faz do grupo focal um espaço privilegiado de coleta de dados. Contudo, como as técnicas não são de utilização universal, tal técnica está condicionada à orientação tanto teórica quanto metodológica da pesquisa e do objeto que está sendo investigado e, também, dos objetivos propostos. Com efeito, o trabalho de campo e a formulação teórica estão intimamente ligados.

Técnicas de coleta de dados, embora muitas vezes mal compreendidas por muitos pesquisadores, ou por eles secundarizadas, são elementos fundamentais em uma pesquisa. É necessário conhecimento e experiência para bem aplicá-las. Neste texto, apresento uma descriçáo analítico-explicativa a respeito da técnica do grupo focal, enfatizando a questão da organização e da sistematização com o intuito puramente contributivo ao maior entendimento e melhor aplicabilidade da técnica.

\section{Por uma definição}

A técnica de grupo focal tem uma história. Ela tem início com outra técnica: a de entrevista em grupo (entrevista focada ou entrevista em profundidade grupal), razão pela qual não raro, equivocadamente, ${ }^{2}$ com ela é confundida. $\mathrm{Na}$ década de quarenta, Robert Merton e sua equipe de colaboradores utilizaram o grupo focal em pesquisas sociais com soldados da II Guerra, visando conhecer a influência exercida sobre eles pelo material de treinamento e as propagandas persuasivas. Tempos depois, Paul Lazarsfeld (1976), teórico da comunicação, adaptou a técnica do grupo focal para pesquisas de Marketing. Daí em diante, outros campos do conhecimento começaram a se valer da técnica para coletar os dados de suas pesquisas. Além disso, ela tem passado por alguns desdobramentos, aparecendo, entre outros, o grupo focal de intervenção (GFI) que pressupóe, além do caráter investigativo, que é comum à técnica, um caráter educativo e informativo. Nele, o mediador também tem a função de provocar discussóes formativas sobre o tema que está sendo investigado (HASSEN, 2002). E o grupo de discussão (GD) que é fundamentado pela linguística, psicanálise e sociologia, com vistas a revelar representaçôes ideológicas dos participantes relativas ao tema em questão e romper com a alienação (IBAÑEZ, 1986).

\footnotetext{
${ }^{2} \mathrm{Na}$ entrevista grupal, as questóes são feitas diretamente aos participantes, e suas respostas passam por uma análise comparativa. No grupo focal, a figura do entrevistador dá lugar ao moderador, ao qual cabe facilitar a discussão entre os participantes, tendo em vista os eixos temáticos.
} 
Seja como for, o grupo focal se define pelo fato de reunir um grupo de sete a doze indivíduos, que não se conhecem e que tenham características comuns, com a finalidade de compartilhar da discussão de um tema específico, mediada por um moderador (facilitador), o qual poderá ser o próprio pesquisador. Ou seja, é uma técnica que visa coletar os dados na interação grupal (DE ANTONI et al., 2001). A interação dos participantes permite acesso a dados e insights que de outro modo seriam difíceis de coletar, tornando-os inacessíveis. Cabe ao moderador criar um ambiente confortável, respeitoso e seguro (confiável), capaz de possibilitar a expressão espontânea e sincera dos participantes, encorajando-os a expressarem suas opinióes, segundo os eixos-temáticos que ele apresenta, discutindo, também, com os outros participantes. É importante enfatizar que a técnica não visa ao consenso; o seu objetivo é buscar, através de encontros com tipos similares de participantes, o maior número de informaçóes sobre o tema, identificando tendências e padrões de percepção. Entretanto, qualquer opinião, mesmo não compartilhada, para efeito de análise e interpretação dos resultados, é considerada do grupo. Para Caplan (1990), o grupo focal se define por ser um pequeno grupo de pessoas reunidas para avaliar conceitos e identificar problemas - num curto espaço de tempo.

\section{Procedimentos práticos}

Alguns pontos são fundamentais à operacionalização dos grupos focais: escolha dos participantes, do moderador, do local dos encontros e duração e, finalmente, a elaboração dos eixos temáticos.

O primeiro ponto, a escolha dos participantes, deve ser tratado com muito cuidado, uma vez que se refere àqueles que irão responder às questóes propostas pela pesquisa. Portanto, devem eles ter capacidade para tanto. Como formarão um grupo de discussão, da fala em debate, algumas características comuns obrigatoriamente devem ser consideradas, variando de acordo com os objetivos da própria pesquisa. A expressão de cada participante sofre a intervenção dos demais, permitindo que a coleta de dados tenha uma dinâmica reflexiva, na qual mudanças de opinióes possam ocorrer. De fato, é preciso que os participantes interajam de tal modo a favorecer trocas, descobertas e participaçóes comprometidas tanto com o tema como com a pesquisa.

A amostra é intencional, podendo variar em termos de faixa etária, sexo, escolaridade, diferenças culturais, entre outras variáveis. Assim, um grupo pode ser formado apenas por mulheres viúvas entre seis a três meses de perda do marido (MORGAN, 1997) para discutir o estado de viuvez; outro, por adolescentes da quinta série de uma escola pública (KEIL, 2012) visando estudar o que eles pensam 
da escola e da sua cultura; outro, com homens e mulheres de baixa renda e escolaridade com vistas a investigar a violência contra mulheres (COUTO, 2006); outro ainda, com pacientes odontológicos, sem plano de saúde, visando estudar os critérios de escolha do dentista (LOPES, 2010) etc.

Em termos do número adequado de participantes para um grupo focal, em geral oscila entre sete e doze. Krueger e Casey (2000) preferem grupos de seis a oito participantes; Gomes e Barbosa (2009) consideram o grupo ideal entre oito e doze participantes. Em minha opinião, dez é o número ideal. Grupos com muitos ou com poucos participantes dificultam a interaçáo entre eles, assim como a fluidez e a riqueza da discussão.

O trabalho do moderador, a maneira pela qual ele apresenta os eixos temáticos que serão discutidos ou que encaminha a discussão possibilitando a interação democrática dos participantes, constitui-se como ponto determinante para o sucesso da pesquisa. O moderador desempenha um papel fundamental de facilitador dos fluxos de comunicação. Com efeito, como afirmam Merton, Kendall e Fiske (1990), cabe a ele explorar ao máximo e em profundidade, de modo não diretivo, cada eixo temático, orientando os participantes de modo que eles não se dispersem e ofereçam informações específicas à investigação. Precisa, ainda, ter habilidade tanto para deixar aflorar os sentimentos dos participantes durante a discussão, sem que isso atrapalhe o andamento do trabalho, como para considerar a relevância do contexto pessoal a partir do qual os participantes engendram suas respostas.

Neste caso, habilidade é competência para pouco intervir no funcionamento do grupo; para não permitir que ocorra monopólio da palavra e polarizações durante a discussão, uma vez que todos devem participar democraticamente; para a escuta ativa; para perceber e explorar alguma opiniáo mais promissora e seus insights; para intervir com perguntas sem emitir a sua própria opinião ou julgamento, rompendo com situações redundantes e repetitivas e, assim, favorecer o avanço da discussão. Para tanto, o moderador deve ter conhecimento do projeto e de seus objetivos e, também, uma boa fundamentação teórica. Além disso, deve ter conhecimento sobre dinâmicas grupais.

A dinâmica do funcionamento do grupo focal inicia com os agradecimentos do moderador pela participação de todos, apresentação dos participantes, referindo características básicas de sua identidade (nome, endereço, profissáo, preferências pessoais de lazer, grau de envolvimento com o tema do grupo focal etc.). Esse é um momento fundamental para a integração dos participantes e depende muito da habilidade e cordialidade do moderador. O clima do encontro deve ser informal. 
Após as apresentaçôes, inclusive as do próprio moderador e do observador (assistente de pesquisa), o moderador deve explicar a finalidade e objetivos da pesquisa, a metodologia para o funcionamento do encontro, inclusive sua reduzida intervençáo, pedindo o consentimento do grupo para que as gravaçóes de áudio e vídeo sejam realizadas, esclarecendo sobre a garantia do anonimato e do sigilo. Deve ele, ainda, falar sobre a presença do observador, que tem como função apenas observar sem participar da discussão, registrar a dinâmica do grupo, ocupar-se dos equipamentos de registro de voz e vídeo. A partir desses entendimentos, têm início as discussões dos eixos temáticos.

Em síntese, a pesquisa inicia logo após a conclusão do protocolo do moderador, isto é, depois de ele:

1. cumprimentar os presentes, agradecendo a participação e salientando a importância de:

2. suas informações para a pesquisa;

3. possibilitar que todos se apresentem;

4. explicar os objetivos do encontro e sua dinâmica;

5. pedir licença para realizar gravaçóes;

6. orientar a respeito do acesso aos resultados da pesquisa.

A escolha do local ideal para a realização do grupo focal é bastante exigente. Exigência essa que varia segundo o tipo que se quer adotar. ${ }^{3}$ No caso do grupo focal presencial (em minha opinião, o tipo com resultados mais satisfatórios), é necessária uma sala especial, sem ruídos, com espelho unidirecional, ${ }^{4}$ uma mesa redonda, ${ }^{5}$ cadeiras dispostas ao seu redor, uma para cada participante, microfones para gravação e câmara de vídeo, ou seja, uma sala que facilite a interação dos participantes. Caso o tema do grupo focal exija algum estímulo (acompanhamento pelos participantes de algum programa de TV, entre outros) será necessária a providência prévia dessas tecnologias.

A duraçáo do grupo focal não deve ser longa; o ideal é que oscile de uma hora e meia a duas horas, tempo suficiente para que os eixos temáticos previstos

\footnotetext{
${ }^{3}$ Alguns pesquisadores têm se utilizado da internet para realizar a técnica do grupo focal.

${ }^{4} \mathrm{O}$ espelho unidirecional permite que observadores acompanhem o grupo focal no momento de sua realização sem serem vistos, porquanto, de um lado do vidro, há um espelho perfeito, mas a transparência é mantida do outro lado.

${ }^{5}$ Devem- se evitar mesas retangulares em razão das cabeceiras, que são lugares de destaque/poder). Se não houver alternativa, ninguém deve sentar-se nas cabeceiras.
} 
possam ser discutidos. Importante enfatizar que não é recomendável planejar mais de cinco eixos temáticos para cada encontro. O número total de encontros é determinado pelos objetivos da própria investigação e da complexidade do tema, não existindo, pois, um número padrão para a técnica.

Neste sentido, observa-se na literatura significativa variabilidade em relação ao número de encontros, indo, por exemplo, de dois encontros por variável (DEBUS, 2004) até vinte encontros (MAGALHÂES e VEIGA, 2000), como por exemplo, em ocasião da pesquisa sobre as manipulações cognitivas da política: o eleitor comum diante da campanha presidencial de 1998. De fato, não há consenso. Uma saída mais segura para estipular o número de encontros para o grupo focal está na afirmação de Debus (2004), isto é, que essa necessidade se esgota quando as informaçóes obtidas deixam de ser novas. Ou seja, quando as respostas dos grupos se tornam repetitivas.

É recomendável que, ao final de cada encontro, o moderador e o observador façam a sua avaliação, destacando pontos que possam integrar os dados coletados (linguagem do corpo etc.) e pontos que devem ser superados nos próximos encontros de grupo focal.

A elaboração dos eixos temáticos (tópicos, guia de temas, roteiro de discussão) é de extrema importância, pois se trata do encaminhamento e condução da coleta de dados. Com efeito, o eixo temático é o fio vermelho da pesquisa, possibilitando maior abrangência, riqueza e eficiência da coleta de dados. Ele funciona como base para o trabalho do moderador, que assim pode explorar, aprofundar questôes, acolher outras vindas dos participantes sem se distanciar dos objetivos da pesquisa. Alguns moderadores preferem apresentar cada eixo temático em forma de pergunta, outros como tópico de discussão. Seja como for, é importante que o moderador não perca de vista que ele não está fazendo entrevistas em grupo.

A elaboração dos eixos temáticos deve acompanhar os objetivos da pesquisa com clareza e objetividade. Eles devem conter poucos itens, de modo a suportar a incorporação de temas, não previstos, mas relevantes, abordados pelos participantes. O grupo focal é uma técnica diretiva e ao mesmo tempo aberta.

É importante chamar a atençáo ao roteiro dos eixos temáticos, o qual deve partir de uma abordagem simples a um nível cada vez maior de complexidade, do explícito para o implícito, possibilitando a integração imediata do grupo. No grupo focal, é pedra de toque tanto a participação democrática como a fluidez da discussão. Portanto, iniciar com questóes simples, pouco ou nada polêmicas promove a integração dos participantes de modo natural, assim como o aumento da complexidade, no grupo já integrado, possibilita que eles pensem, observem, escutem, 
relacionem suas opiniōes com as demais, argumentem, aceitem pensamentos divergentes e exponham seus sentimentos.

\section{Análise e interpretação dos resultados}

A análise e a interpretação dos resultados do grupo focal se iniciam com a transcrição e leitura das fitas cassetes e de vídeo, formando blocos de acordo com os eixos temáticos, portanto, com os objetivos da pesquisa. Cada bloco deve ser analisado separadamente; no transcorrer da análise, é importante destacar e tecer comentários dos pontos relevantes.

Nesse processo, dois planos são extremamente relevantes: os planos horizontal e vertical. Aquele se constitui a partir das opinióes, comentários e argumentos, convergentes e divergentes, dos participantes durante a discussão no grupo focal; este se constitui a partir da comparação entre todos os grupos focais. Nesse plano, dados relevantes, tendências, padrões, opinióes solidamente mantidas, detalhes originais são identificados.

Para maior facilidade no processo de análise, recomenda-se produzir um quadro, com as ideais predominantes. Nele devem constar os conteúdos oriundos da discussáo dos participantes (respostas) tanto do plano horizontal como do plano vertical. Ao analisar esses conteúdos, é importante contextualizar o momento em que foram ditos, em que circunstância (tom e intensidade), qual o nível de concordância interna (precisão da resposta, hesitação, mudança por pressão do grupo etc.) e qual o significado.

Iervolino e Pelicone (2001) recomendam que a análise seja feita a partir de um sumário etnográfico e da codificação dos dados, utilizando o método de análise de conteúdo. Para os pesquisadores, a combinação dos dois potencializa o rigor da coleta de dados.

Claro está que o pesquisador não pode analisar literalmente os comentários, mas deve proceder a uma análise profunda com vistas à compreensão de seu significado. É importante considerar o contexto social dos participantes, uma vez que os dados coletados são potencialmente subjetivos.

\section{Vantagens e desvantagens do grupo focal}

Tal qual as outras técnicas de investigação, o grupo focal apresenta vantagens e desvantagens. Há unanimidade entre os pesquisadores em considerar o baixo custo e a rapidez nos resultados como suas maiores vantagens. Entretanto, há outras vantagens largamente reconhecidas. Em minha opiniáo, a maior delas é o próprio formato do grupo, o qual, sendo aberto, permite que se explorem em profundidade 
os temas em discussão e, também, que apareçam questões as quais o pesquisador não havia pensado em inserir na investigação ou simplesmente desconhecia. Um tema em debate está calcado na troca de experiências e de opinióes e faz emergir as crenças de cada um, os modos particulares de agir e de sentir, isto é, faz emergir muitos elementos. Saber aproveitá-los, explorá-los vai depender da habilidade do moderador.

Outra grande vantagem é que com a interação dos participantes torna-se possível observar se de fato o que eles dizem é apenas um estereótipo ou se realmente pensam aquilo que estão comunicando. A intervenção do moderador e do próprio grupo possibilita que o participante reflita sobre aspectos que isoladamente náo o faria. E isso implica o aprofundamento da discussão. Nesse caso, o levantamento dos dados diretamente relacionado ao tema da investigação é bastante eficiente.

A técnica de grupo focal também apresenta desvantagens. Duas delas dependem da boa escolha dos participantes e da habilidade do moderador. A primeira tem relação com a seleção dos participantes, os quais devem ter conhecimento / experiência / opinióes sobre o assunto que está sendo investigado. Não é possível participar de um grupo focal sem as características fundamentais definidas pelos objetivos da investigação. Assim, por exemplo, se a pesquisa visa investigar sentimentos ligados à viuvez, obrigatoriamente, os participantes do grupo devem ter essa experiência. A segunda, a habilidade do moderador, como já escrevi anteriormente, é decisiva para a excelência da coleta de dados e, consequentemente, para a qualidade da investigação. Com efeito, muitas situaçôes oriundas da dinâmica de grupo não raramente ocorrem (desvio do tema em discussão, monopólio da palavra, conformidade face à opinião oprimida etc.) e podem desvirtuar a interação do grupo, comprometendo a coleta de dados.

Alguns pesquisadores consideram como desvantagem a não garantia real do anonimato dos participantes e que, diante de temas polêmicos, eles tenderiam a concordar com o senso comum, não emitiriam sua opinião verdadeira ou concordariam com a maioria dos entrevistados. Essa não é a minha opinião.

\section{Considerações finais}

A técnica de grupo focal, portanto técnica qualitativa, permite pesquisar, em curto espaço de tempo e baixo custo, temas extremamente complexos, responder a questóes relevantes e produzir conhecimento. Entretanto, a escolha da técnica depende dos referenciais que orientam a pesquisa e dos seus objetivos.

Tal técnica favorece a construção do pensamento em grupo, revelando suas contradições, desaprovaçôes, aprovações, concordâncias. Por ser uma técnica em que a integração dos participantes e a expressão democrática das suas opiniões são 
aspectos fundamentais, a seleção deles deve ser muito criteriosa. Como também criteriosa deve ser a escolha do moderador (quando não é o próprio pesquisador que realiza os grupos focais) e do observador, os quais precisam ter, dentre outras habilidades, boa capacidade crítico-reflexiva. Esses aspectos mencionados são extremamente relevantes para o encaminhamento qualificado da pesquisa em conformidade com os seus objetivos.

É importante reafirmar aqui, também, que são muitas as possibilidades da utilização da técnica dos grupos focais. Elas vão da coleta de dados para pesquisas acadêmicas, passando por sua utilizaçáo em organizações formais com vistas à tomada de decisões, elaboração de diagnósticos e avaliaçóes, geração de novas ideias, invençôes e projetos, chegando ao campo da saúde, com programas educativos para grupos específicos; e ao marketing, entre tantas outras possibilidades, como no campo da política. Tal técnica pode ser utilizada sempre que se quer conhecer crenças, valores, opinióes, comportamentos etc. quando o foco de análise for um grupo.

Em síntese, a técnica do grupo focal possibilita a coleta de dados dentro de um processo intersubjetivo que envolve a participação democrática do grupo, permitindo a partir da reflexão crítica - respostas aprofundadas e confiáveis.

Ivete Manetzeder Keil é Doutora em Antropologia pela Sorbonne Paris V, e Pós-doutora em Antropologia pela École des Hautes Études en Sciences Sociales - EHESS. E-mail: ivetek@hotmail.com.

\section{Referências}

CAPLAN, Stanley. Using focus group methodology for ergonomic design. Ergonomics. London. v. 33, n. 5, 1990.

COUTO, M. T. Et alii. Concepçóes de gênero entre homens e mulheres de baixa renda e escolaridade acerca da violência contra a mulher, São Paulo / Brasil. Ciência e saúde coletiva. v. 11. suppl. 0. Rio de Janeiro, 2006.

DE ANTONI, C. Et alii. Método qualitativo de pesquisa com adolescentes em situação de risco. Arquivos Brasileiros de Psicologia. 53(2). Imago Editora. Rio de Janeiro, 2001.

DEBUS, M. Manual de excelência em la investigación mediante grupos focales. In: E. Esperidião (org.). Reflexões sobre a utilização do grupo focal como técnica de pesquisa. Fundação Editora de UNESP. São Paulo, 2004. 
GOMES, M. E. S., BARBOSA, E. F. A técnica de grupos focais para obtenção de dados qualitativos. Educativa. Instituto de Pesquisas e Inovaçóes Educacionais. Campinas, 2009.

HASSEN, M. N. Grupos Focais de Intervenção no projeto Sexualidade e Reprodução. Horizontes antropológicos. v. 8 n. 17. Porto Alegre: June, 2002.

IBAÑEZ, J. Más allà de la sociologia. El grupo de discusión: técnica y crítica. Siglo XXI de España Editores. Madrid, 1986.

IERVOLINO, S. A.; PELICIONE, M. C. A utilização do grupo focal como metodologia qualitativa na promoção da saúde. Revista Escola de Enfermagem, USP. v. 35. n. 2 . p. 115-21. São Paulo, 2001.

KEIL, I. O que pensam os adolescentes da escola pública sobre a escola e sua cultura. Relatório da ABMP, São Paulo, 2012.

KRUEGER, R. A.; CASEY, M. A. Focus groups. A practical guide for applied research. $3^{\mathrm{a}}$ Ed. Thousand Oaks: Sage, 2000.

LAZARSFELD, P.F. Qualitative analysis: Historical and critical essays. Allyn \& Bacon. Boston, 1976.

LOPES, K. M.G. Grupos focais: uma estratégia para a pesquisa em saúde. Revista Brasileira de Odontologia, Rio de Janeiro: Versão eletrônica. Jun. 7, 2010.

MAGALHÁES, R. F.; VEIGA, L. Manipulaçóes cognitivas do político: o eleitor comum diante da campanha presidencial de 1998. In: FIGUEIREDO, Rubens (org.) Marketing político e persuasão eleitoral. Fundação Konrad Adenauer. São Paulo, 2000.

MERTON, R. K., at alii. The focused interview: a manual of problems and procedures. Free Press. New York, 1990.

Morgan, D. Focus group as qualitative research. Qualitative Research Methods Series. 16. Sage Publications. London, 1997.

PICHON-RIVIÈRE, E. O processo grupal. Martins Fontes. São Paulo, 1998.

Texto recebido em 09 de março de 2015. Aprovado em 25 de março de 2015. 
